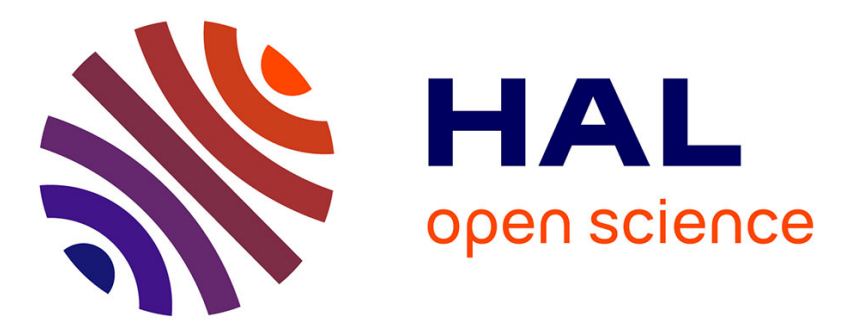

\title{
Double-Network Heparin Dynamic Hydrogels: Dynagels as Anti-bacterial 3D Cell Culture Scaffolds
} Han Cui, Qimeng Wang, Ye Zhang, Mihail Barboiu, Yan Zhang, Jinghua Chen, Q Cui, Y Wang

\section{- To cite this version:}

Han Cui, Qimeng Wang, Ye Zhang, Mihail Barboiu, Yan Zhang, et al.. Double-Network Heparin Dynamic Hydrogels: Dynagels as Anti-bacterial 3D Cell Culture Scaffolds. Chemistry - A European Journal, 2021, 27 (24), pp.7080-7084. 10.1002/chem.202005376 . hal-03408598

\section{HAL Id: hal-03408598 \\ https://hal.science/hal-03408598}

Submitted on 29 Oct 2021

HAL is a multi-disciplinary open access archive for the deposit and dissemination of scientific research documents, whether they are published or not. The documents may come from teaching and research institutions in France or abroad, or from public or private research centers.
L'archive ouverte pluridisciplinaire HAL, est destinée au dépôt et à la diffusion de documents scientifiques de niveau recherche, publiés ou non, émanant des établissements d'enseignement et de recherche français ou étrangers, des laboratoires publics ou privés. 


\title{
Double-network Heparin Dynamic Hydrogels: Dynagels as Anti- bacterial 3D Cell Culture Scaffolds
}

\author{
Han Cui, ${ }^{[a]}$ Qimeng Wang, ${ }^{[a]}$ Ye Zhang, ${ }^{[a]}$ Mihail Barboiu, ${ }^{*[b]}$ Yan Zhang ${ }^{*[a]}$ and Jinghua Chen ${ }^{*[a]}$
}

[a] H. Cui, Q. Wang, Y. Zhang, Dr. Y. Zhang, Prof. J. Chen

Key Laboratory of Carbohydrate Chemistry and Biotechnology, Ministry of Education, School of Pharmaceutical Sciences Jiangnan University

1800 Lihu Avenue, Wuxi, 214122, P.R. China.

E-mail: chenjinghua@jiangnan.edu.cn; zhangyanyz@jiangnan.edu.cn

[b] Dr. M. Barboiu

Institut Europeen des Membranes, Adaptive Supramolecular Nanosystems Group

University of Montpellier, ENSCM-CNRS

Place E. Bataillon CC047, Montpellier, F-34095, France

E-mail:mihail-dumitru.barboiu@umontpellier.fr

Supporting information for this article is given via a link at the end of the document

\begin{abstract}
Double cross-linked dynamic hydrogels-dynagels have been prepared through reversible imine bonds and supramolecular interactions, which showed good $\mathrm{pH}$ responsiveness, injectability, self-healing property and biocompatibility. With the further encapsulation of heparin, the obtained hydrogels exhibited good anti-bacterial activity and promotion effects for 3D cell culture.
\end{abstract}

Hydrogels are functional smart multi-responsive materials with broad applications in various research areas, like drug delivery and tissue engineering. ${ }^{[1]}$ Compared to $2 \mathrm{D}$ cell culture environments, the 3D cross-linked hydrogels show advantages in imitating the natural cell behaviours and revealing cell-cell and cell-matrix interactions. ${ }^{[2]}$ With the development of multicomponent materials, hydrogels with simultaneous various functions have been developed. ${ }^{[3]}$ Moreover, adjustable biochemical cues and mechanical properties can provide the hydrogels with extracellular matrix (ECM)-like environment, which became an ideal platform for 3D cell culture and control the cell growth. ${ }^{[4-5]}$

Most of the existing hydrogel scaffolds are covalently cross-linked through the static networks that induce steric limitations for the cell growth. On the other hand, imine ${ }^{[6]}$ acylhydrazone,${ }^{[7]}$ boronic-ester ${ }^{[8]}$ disulfide,${ }^{[9]}$ Diels-Alder ${ }^{[10]}$ reversible covalent bonds, opens up opportunities for the generation of dynamic hydrogels- Dynagels, which are defined as hydrogels that are dynamic on both covalent and supramolecular levels. ${ }^{[11]}$ With the constant broken down and restoration of their reversible bonds, the dynamic hydrogels show excellent responsiveness and functions, ${ }^{[11]}$ i.e. self-healing, ${ }^{[12]}$ shape memory ${ }^{[13]}$ or injectability, ${ }^{[14]}$ leading to broad applications in areas of enzyme catalysis, ${ }^{[15]}$ recyclable plastics, ${ }^{[16]}$ membranes, ${ }^{[17]}$ drug delivery, ${ }^{[18]}$ wound healing, ${ }^{[19]}$ tissue engineering, ${ }^{[20]}$ etc.

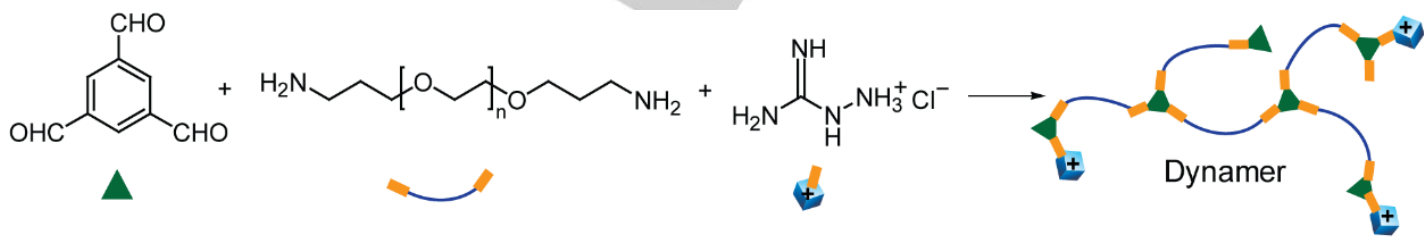

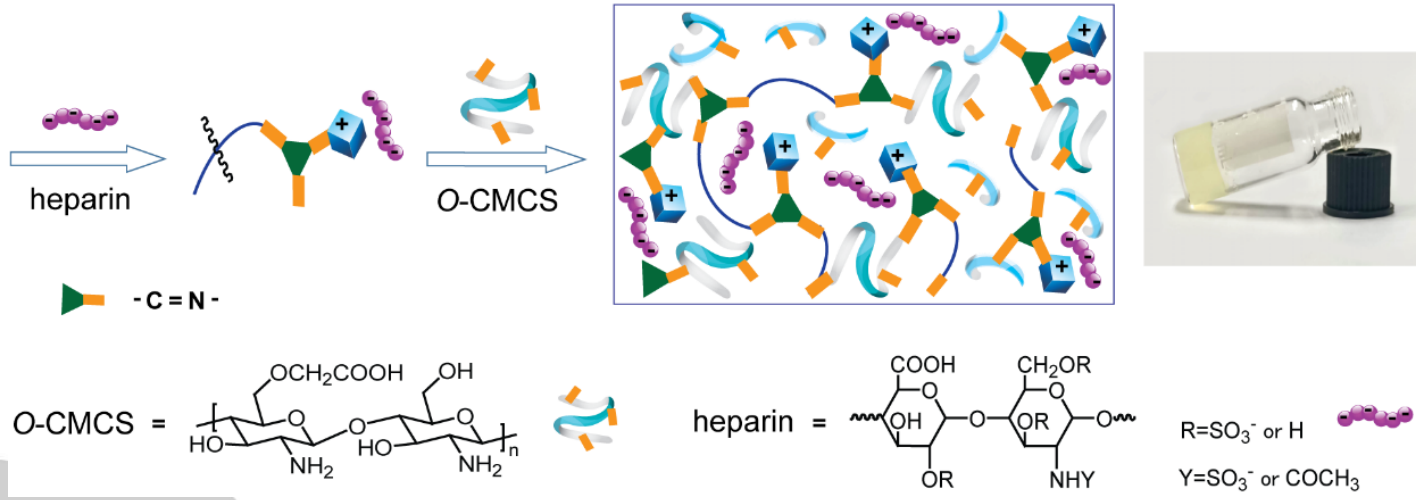

Figure 1. Synthesis of the Dynamer-O-CMCS-guanidinium dynagels for heparin encapsulation. 
Heparin is a natural glycosaminoglycan able to interact with diverse key proteins, showing numerous biological activities. ${ }^{[21]}$ For example, besides well-known anticoagulation function, heparin is also associated with anti-tumor, ${ }^{[22]}$ antimetastatic $^{[23]}$ and anti-microbial effects. ${ }^{[24]}$ In recent studies, heparin have been incorporated into hydrogels, leading to applications of inducing the formation of human renal tubules, ${ }^{[25]}$ hepatocyte culture, ${ }^{[26]}$ delivery of drugs ${ }^{[27]}$ or growth factors, ${ }^{[28]}$ promoting wound healing, ${ }^{[29]}$ etc. The use of dynamic covalent chemistry into heparin hydrogels is an unreported strategy, and we speculate that may further lead to multi-functional materials with stimuli responsiveness and spatial adaptiveness. Meanwhile, chitosan is another natural polysaccharide with antibacterial property and biocompatibility. ${ }^{[0]}$ In addition, the abundant amino groups in chitosan structure can form reversible imine bonds, showing potentials for the fabrication of dynamic adaptive materials. ${ }^{[31]}$

Herein, we have first designed imine-dynamers decorated with positively charged guanidinium groups that interact with the negatively charged heparin in water. The water-soluble $O$ Carboxymethyl chitosan (O-CMCS) with exposed amine group was then used as a secondary imine cross-linking scaffold for hydrogel preparation. The resulted double-network constitutional hydrogels cross-linked via reversible imine covalent bonds and supramolecular $\mathrm{H}$-bonding and electrostatic interactions showed excellent $\mathrm{pH}$ responsiveness, injectability and self-healing properties. The heparin-encapsulated hydrogels are biocompatible and show the promotion effects of cell proliferation, for anti-bacterial and 3D cell culture biomedical applications.

The fabrication of hydrogels was initiated by the synthesis of Dynamer from 1,3,5-benzenetricarboxaldehyde, 1 poly (ethyleneglycol)bis(3-aminopropyl)-terminated, 2 and aminoguanidine hydrochloride, 3 in $\mathrm{MeOH}$ at $60^{\circ} \mathrm{C}$ (Figure 1), in order to react through imine bonds. From the ${ }^{1} \mathrm{H}$ NMR spectra of the synthesized Dynamer (Figure S1), two new aldehyde peaks (10.13 ppm and $10.06 \mathrm{ppm}$ ) and some high-field shifted aromatic peaks and newly formed imine peaks showed up at 8.5-8.1 ppm, indicating the formation of mono and di-substituted imine compounds. The molecular mass of the former dynamer 1.2 has been previously reported by using DOSY NMR: $M_{n}=15$ 000-18 $000 \mathrm{~g} \mathrm{~mol}^{-1}$ corresponding to $\sim 10-12$ PEG monomers. ${ }^{[2 \mathrm{~d}]}$ With the addition of negatively charged heparin, dynamer can interact through electrostatic interactions, but still in solution state. Subsequently, variable amounts of O-CMCS were added to the mixture to react with the remaining extra aldehydes, to form the secondary dynamic imine cross-linked network of hydrogels. The test for gelation time was replicated 3 times by bottle-inversion method. With the increased content of O-CMCS within $\sim 200 \mu \mathrm{L}$ of total sample, the gelation time can be obviously shortened, from $\sim 1 \mathrm{~h}$ to $85 \mathrm{~s}$, when 2 eq. to 8 eq. of $\mathrm{NH}_{2}$ in $\mathrm{O}$-CMCS /remaining aldehyde group in dynamer were used. The use of 16 eq. O-CMCS led to too fast gelation process, resulting in an uneven distribution of the constituents inside the hydrogel. Thus, 8 eq. of O-CMCS was chosen as optimal for further studies, when various hydrogels with the variable dynamer to heparin molar ratios of $1: 2\left(\mathbf{G H}_{1-2}\right), 1: 4$ $\left(\mathbf{G H}_{1-4}\right)$ and 1:6 $\left(\mathbf{G H}_{1-6}\right)$ were prepared.

The imine-bond formation was confirmed by Fourier transform infrared (FTIR) spectroscopy. As shown in Figure S2, the aldehyde vibration band $v_{\mathrm{C}=\mathrm{O}}$ at $1692 \mathrm{~cm}^{-1}$ from 1 and dynamer spectra completely disappeared, while a new $v_{\mathrm{C}=\mathrm{N}}$ vibration band can be observed at $1640 \mathrm{~cm}^{-1}$ in the final hydrogels' spectra. Thereafter, Scanning Electron Microscopy (SEM) were used to analyse the cross-sectional morphology of the hydrogels, where porous structures were observed in all the tested hydrogels, with no obvious differences among the hydrogels bearing varied amounts of heparin (Figure S3-4).

Scaffolds with desirable mechanical stability are highly important for biomedical applications. According to the results of amplitude sweep, $1 \%$ strain value was selected to determine the rheological behaviours of the hydrogels (Figure S5a). Under this strain, the storage modulus ( $\left.\mathrm{G}^{\prime}\right)$ of $\mathbf{G H}_{\mathbf{1 - 2}}$ was recorded as $700 \mathrm{~Pa}$. When the amount of O-CMCS was doubled, the $\mathrm{G}^{\prime}$ value can be increased to as high as $2000 \mathrm{~Pa}$ (Figure S5b). Lowering the concentration of $\mathrm{O}-\mathrm{CMCS}$, led to significantly decreased G' values, indicating the critical strengthening role of the O-CMCS for the mechanical properties of the hydrogels via double cross-linking. Oppositely, an increased content of heparin did not make a large difference for G' values, with the biggest number obtained from $\mathbf{G H}_{1-2}$. These results also indicated that the mechanical behaviours of the hydrogels can be easily adjusted according to the specific application requirements.

a)
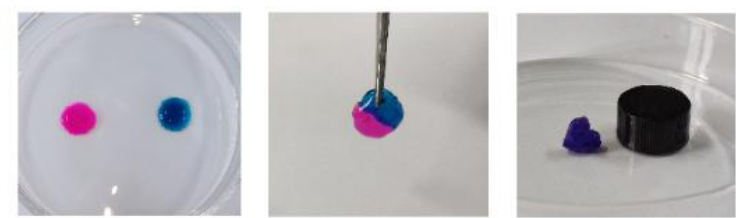

b)

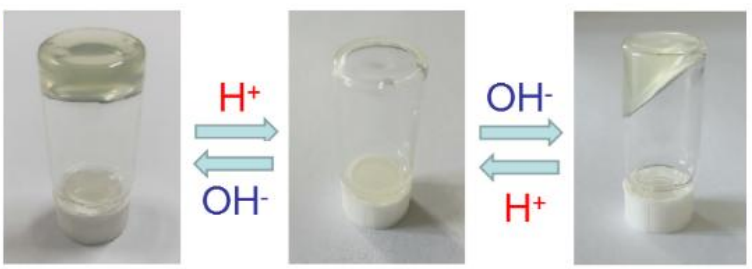

c)
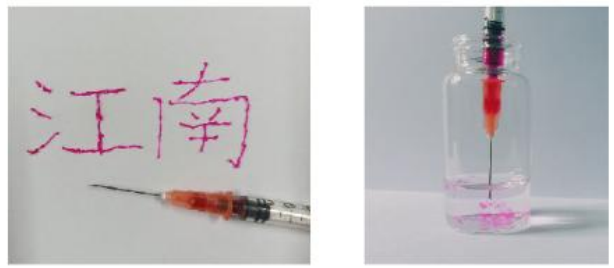

Figure 2. a) Self-healing from two halves and mashed pieces, b) $\mathrm{pH}$ responsiveness acid-base sol-gel transition cycles and c) good injectability of the hydrogel $\mathrm{GH}_{1-2}$

The reversible nature of the double cross-linked networks can contribute to the self-healing properties of the hydrogels. Therefore, continuous step changes of oscillatory strain (1 to $300 \%)$ were performed under the same frequency $(10 \mathrm{rad} / \mathrm{s})$ to estimate the strain-induced damage and re-healing efficiency of the hydrogels (Figure S6b-d). Under a high strain of 300\%, G" values were higher than $G^{\prime}$, indicating the damaged structures for all hydrogels. When the strain was switched to $1 \%$, both $\mathrm{G}^{\prime}$ and $G$ " were recovered to the near original value, with the restoration of the internal structure of the hydrogels. $\mathbf{G H}_{1-2}$ 
hydrogel showed the best self-healing property, after three times consecutive step strains tests, the transient recovery rate of deformation was about $93 \%$. Meanwhile, the $\mathrm{G}^{\prime}$ of the $\mathbf{G H}_{1-4}$ and $\mathbf{G H}_{1-6}$ can only reach $68 \%$ and $84 \%$ of the initial value, respectively, probably coming from the weak interactions induced by extra charges. In order to further check the selfhealing properties of the hydrogels, two red and blue stained halves of $\mathbf{G H}_{1-2}$ respectively, were put next to each other with tweezers, and the entire gel can be lifted after $20 \mathrm{~min}$, leaving no visible gaps in the jointed interface (Figure 2a). Moreover, the other two halves of $\mathbf{G H}_{1-2}$ were completely mashed and mixed into a heart shape, leading after $20 \mathrm{~min}$ to a whole piece of selfstanding hydrogel. These experiments showed the excellent, strong and fast re-healing ability of the hydrogels from either two halves or mashed pieces.

Owing to the reversible imine bonds, the dynamic hydrogels possess $\mathrm{pH}$ responsiveness. By adding $1 \mathrm{M} \mathrm{HCl}$ onto the hydrogel surfaces until $\mathrm{pH}=5$, significant gel-sol transitions were observed for all samples, resulting in turbid liquid solutions (Figure 2b). In addition, this transformation was completely reversible to sol-gel transitions by addition of $1 \mathrm{M} \mathrm{NaOH}$ solution until $\mathrm{pH}=7$. The reversible $\mathrm{pH}$ responsiveness and sol-gel transition have been illustrated during five repeated acid-base additions cycles, suggesting that such dynamic hydrogels can be used in interesting applications like targeted drug delivery, cell culture and tissue engineering. Moreover, as shown in Figure 2c, $\mathbf{G H}_{1-2}$ presents good injectability, which can be injected directly into the PBS solution, making a more convenient usage for biomedical applications. This injectability was also measured with the viscosity plotted against varied shear rates. As can be seen in Figure S7, the cohesive forces of hydrogels were destroyed at high shear rates, making the viscosity of the hydrogels low enough to be injected through syringe.

The swelling properties of the hydrogels were next evaluated. All hydrogels hold high swelling ratios, and the equilibrium state was reached in $6 \mathrm{~h}$ (Figure $3 \mathrm{a}$ ). $\mathbf{G H}_{1-6}$ showed the highest swelling ratio of $1500 \%$, followed by $\mathbf{G H}_{1-4}(1400 \%)$ and $\mathbf{G H}_{1-2}(1300 \%)$. These results indicated that increased excess amount of heparin did not contribute to higher crosslinking networks, oppositely, slightly loosen structures were found in $\mathbf{G H}_{1-4}$ and $\mathbf{G H}_{1-6}$. The high swelling ability of the hydrogels can also be correlated to the release of heparin from the gel networks. Based on the previously recorded alcian blueheparin standard curve (Figure S9), hydrogel $\mathbf{G H}_{1-2}$ showed a release of $30 \%$ heparin in the first $6 \mathrm{~h}$, and finally reached $85 \%$ heparin release rate in $7 \mathrm{~d}$. In comparison, $\mathbf{G H}_{1-4}$ and $\mathbf{G H}_{1-6}$ had a higher heparin burst release in the first $6 \mathrm{~h}$, and the cumulative release were reached about $80 \%$ and $85 \%$, respectively, in a shortened time frame of $36 \mathrm{~h}$ (Figure $3 \mathrm{~b}$ ).

All hydrogels showed fast degradation degrees in vitro (Figure S8) within the first day, recorded as $20 \%, 25 \%$ and $28 \%$ for $\mathbf{G H}_{1}$. 2, $\mathbf{G H}_{1-4}$ and $\mathbf{G H}_{1-6}$, respectively. Then the degradation rates slowed down and reached equilibrium around 25 days, with the degradation degrees of $53 \%$. The loss of hydrogel masses can be contributed to the breaking down of imine bonds and the decrosslinking of the main components after long time incubation in PBS ( $\mathrm{pH} 7.4$ ), leading to the loosened structures, which can provide the cells with more space inside the hydrogels for continuous growth.
Since both O-CMCS and heparin have been reported with anti-bacterial effect, the hydrogels were subjected for in vitro anti-bacterial assays. First, turbidity method was used to analyze the influences of heparin containing hydrogels on the bacterial growth curves. Compared to the control group with the absence of hydrogels, the OD values for the bacterial suspensions containing hydrogels stayed very low, close to zero for the initial $12 \mathrm{~h}$ for the case with $\mathbf{G H}_{1-6}$, while the presence of $\mathbf{G H}_{1-2}$ and $\mathbf{G H}_{1-4}$ led to increased OD values of around 0.4 (Figure S10a). These results indicated good bacterial inhibitory property of the prepared hydrogels. Moreover, by using poured-plate method, the inhibition zone measurement was conducted for $\mathbf{G H}_{1-2}, \mathbf{G H}_{1-4}$ and $\mathbf{G H}_{1-6}$. As a result, the inhibition zones were clearly observed for all hydrogels (Figure S10b), with the bacteriostatic diameter of $\mathbf{G H}_{1-6}$ recorded as $15 \mathrm{~mm}$, slightly higher than as measured for $\mathbf{G H}_{1-2}(12 \mathrm{~mm})$ and for $\mathbf{G H}_{1-4},(13 \mathrm{~mm})$, consistent with the amounts of heparin encapsulated inside the hydrogels.
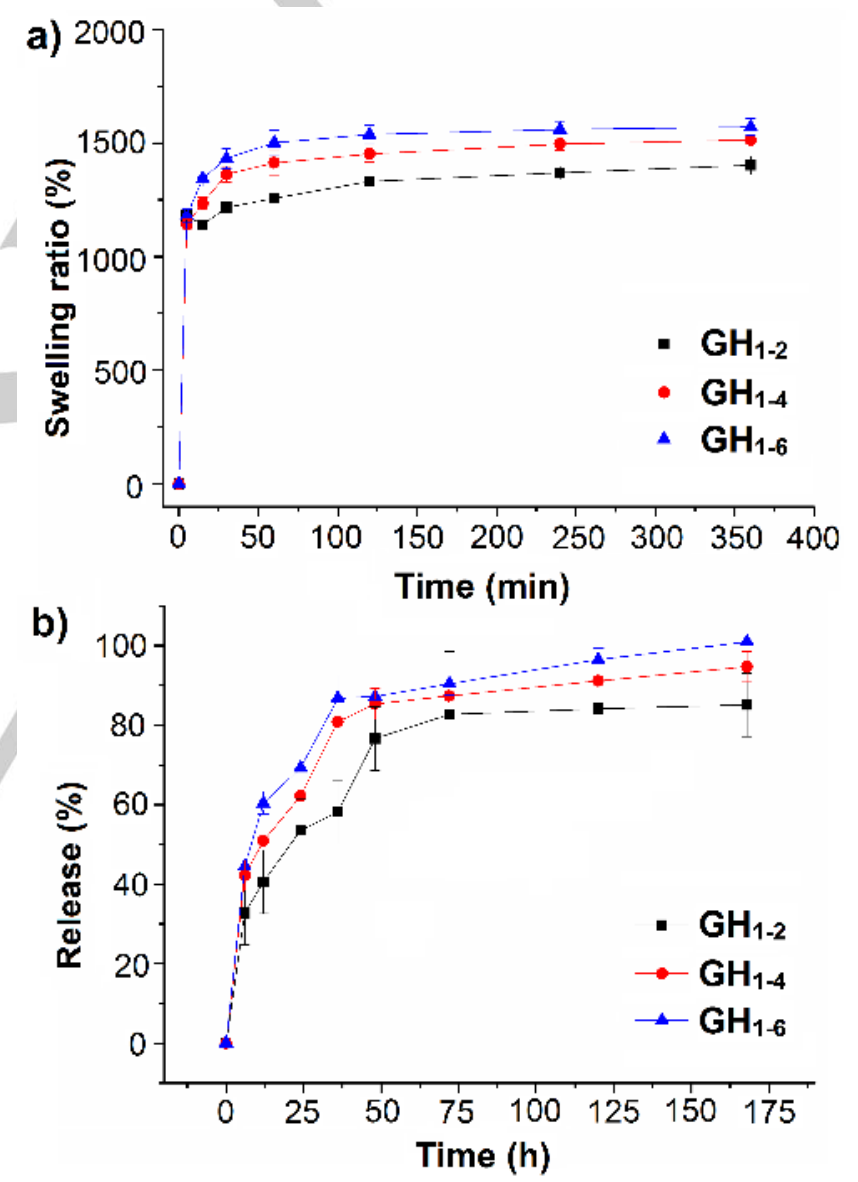

Figure 3. a) Swelling $(n=4)$ and b) heparin release $(n=3)$ of the hydrogels

Then, MTT assays were carried by incubation of 3T3 fibroblasts with gradient concentration of hydrogel extractions from $\mathbf{G H}_{1-2}, \mathbf{G H}_{1-4}$ and $\mathbf{G H}_{1-6}$, and the cell viability was quantified. With culture media as the control group, although lower cell viability was observed with the increased concentration of hydrogel extractions, the relative cell viability value still remained higher than $80 \%$ after co-culture with $100 \%$ hydrogel extractions for $48 \mathrm{~h}$ (Figure 4a), proven good biocompatibility of the hydrogels $\mathbf{G H}_{1-2}, \mathbf{G H}_{1-4}$ and $\mathbf{G H}_{1-6}$. 
Considering the interactions between heparin and basic fibroblast growth factor (bFGF), the heparin containing hydrogels can also be a bFGF carrier for beneficial influences on further 3D cell culture applications. As a result, the presence of bFGF effectively promoted the cell proliferation, with the relative cell viability recorded as higher than $150 \%$ for the group of $100 \%$ hydrogel extraction (Figure 4b), much higher than all the other tested samples. Compared with the traditional 2D cell culture, 3D hydrogel environment can better mimic the actual cell growth situation in ECM. In the current study, 3T3 cells were incubated with the dynamer first, before the initiation of gelation processes for $\mathbf{G H}_{1-2}, \mathbf{G H}_{1-4}$ and $\mathbf{G H}_{1-6}$. After $72 \mathrm{~h}$ of 3D culture, the 3T3 cells were stained with calcein acetoxymethyl ester (calcein-AM, green-fluorescence) and propidium iodide (PI, red-fluorescence) for the observation of live and dead cells respectively by using confocal laser scanning microscopy (CLSM). As can be seen in Figure $4 \mathrm{c}-\mathrm{e}$, the cells in $\mathbf{G H}_{1-2}$ were basically all alive (green colour), while the cells in $\mathbf{G H}_{1-4}$ and $\mathbf{G H}_{1-6}$ showed sporadic red colour (dead), accompanied by decreased cell density, indicating better mechanical and biocompatible environment of $\mathrm{GH}_{1-2}$ for cell growth, which was in consistent with MTT results. This phenomenon can be probably attributed to the absence of heavily excessed heparin and the tighter cross-linked structures in $\mathbf{G H}_{1-2}$. Furthermore, $\mathbf{G H}_{1-2}$ was selected to load bFGF and used for 3D culture of 3T3 cells under the same conditions. By comparing the images from cell culture of $72 \mathrm{~h}$ (Figure 4f), 3T3 cells were confirmed to maintain good proliferating inside the hydrogel containing bFGF, with even higher cell density than $\mathbf{G H}_{1-2}$ alone, demonstrating the ideal 3D environment provided by these dynamic hydrogels.
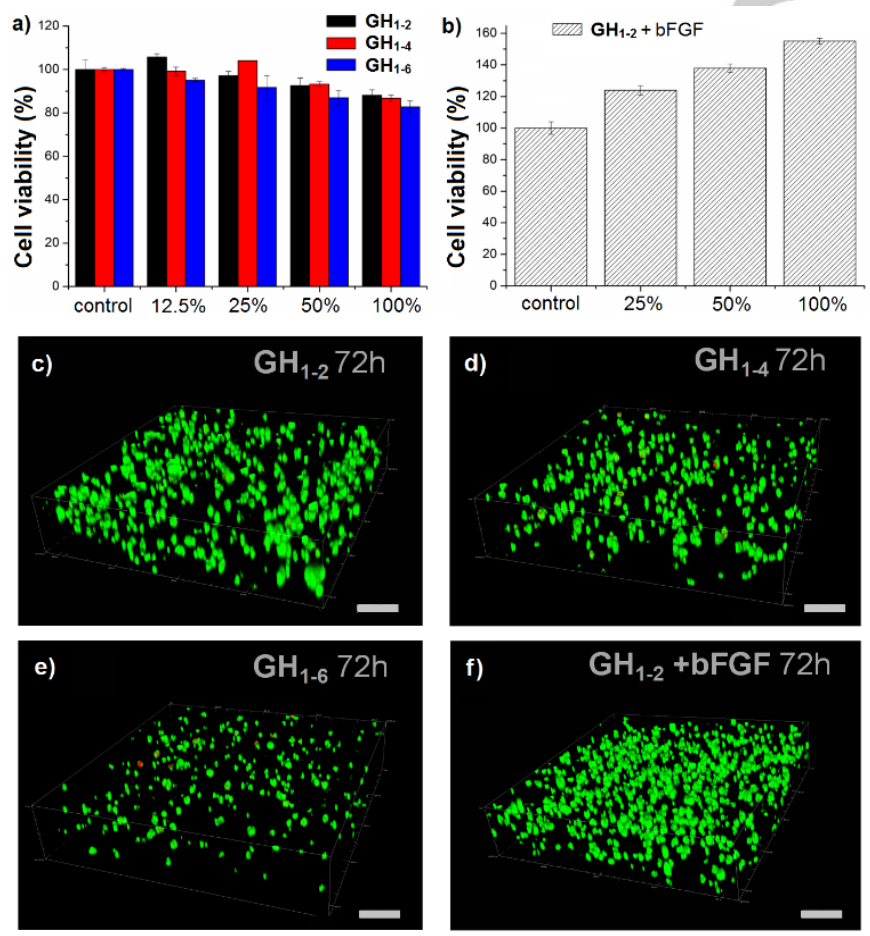

Figure 4. Cytotoxicity assay of a) $\mathbf{G H}_{1-2}, \mathbf{G H}_{1-4}, \mathbf{G H}_{1-6}$ and b) $\mathbf{G H}_{1-2}$ carrying growth factor $b F G F$. Data are represented as mean $\pm S D(n=6)$. Confocal laser scanning microscopy (CLSM) images of $3 T 3$ cells $3 D$ cultured inside hydrogels c) $\mathbf{G H}_{1-2}$, d) $\mathbf{G H}_{1-4}$, e) $\mathbf{G H}_{1-6}$ and f) $\mathbf{G H}_{1-2}$ with bFGF for $72 \mathrm{~h}$ in vitro, cells were stained green with Calcein- $\mathrm{AM}$ and red with Propidium lodide (PI). Scale bar: $100 \mu \mathrm{m}$
In conclusion, we present here an imine-PEGylated dynamer containing positively-charged guanidinium groups used for encapsulation of heparin and for the formation of dynamic biocompatible hydrogels via double cross-linking with O-CMCS. The dynagels have displayed interesting advantages over other existing covalently or physically cross-linked heparin hydrogels with excellent $\mathrm{pH}$ responsiveness, injectability and self-healing properties. In the subsequent applications, the dynagels showed good anti-bacterial activity and exhibited as an excellent growth matrix for the 3T3 cells, where the presence of growth factor bFGF highly promoted the 3D cell culture rate. The current study exemplified a new method for the fabrication of heparin hydrogels through double cross-linked dynamic PEGylated / O-CMCS networks, showing great potentials for wider biomedicine research, for example, tissue engineering directed biomaterials design.

\section{Acknowledgements}

This work was supported by National Natural Science Foundation of China (21574059, to JC), Natural Science Foundation of Jiangsu Province (BK20180625, to YZ) and National First-class Discipline Program of Light Industry Technology and Engineering (LITE2018-20, to JC and YZ).

Keywords: Dynamic hydrogels $\cdot$ Heparin $\cdot 3 \mathrm{D}$ cell culture $\bullet$ Antibacterial $\cdot$ growth factor

[1] a) L. Yang, Y. Li, Y. Gou, X. Wang, X. Zhao and L. Tao, Polym. Chem. 2017, 8, 3071-3076; b) V. Yesilyurt, M. J. Webber, E. A. Appel, C. Godwin, R. Langer and D. G. Anderson, Adv. Mater. 2016, $28,86-91$; c) U. Freudenberg, Y. Liang, K. L. Kiick and C. Werner, Adv. Mater. 2016, 28, 8861-8891; d) C. Diaferia, G. Morelli and A. Accardo, J. Mater. Chem. B 2019, 7, 5142-5155.

[2] a) B. M. Baker and C. S. Chen, J. Cell Sci. 2012, 125, 3015-3024; b) A. D. Arya, P. M. Hallur, A. G. Karkisaval, A. Gudipati, S. Rajendiran, V. Dhavale, B. Ramachandran, A. Jayaprakash, N. Gundiah and A. Chaubey, ACS Appl. Mater. Interfaces 2016, 8, 22005-22017; c) C. Zhang, B. Wu, Y. Zhou, F. Zhou, W. Liu and Z. Wang, Chem. Soc. Rev. 2020, 49, 3605-3637.

[3] a) B. O. Okesola, S. Ni, B. Derkus, C. C. Galeano, A. Hasan, Y. Wu, J. Ramis, L. Buttery, J. I. Dawson, M. D'Este, R. O. C. Oreffo, D. Eglin, H. Sun and A. Mata, Adv. Funct. Mater. 2020, 30, 1906205; b) H. K. Lau and K. L. Kiick, Biomacromolecules 2015, 16, 28-42; c) Q. Cheng, Z. Cao, A. Hao, Y. Zhao and P. Xing, ACS Appl. Mater. Interfaces 2020, 12, 15491-15499.

[4] a) L. Lv, H. Liu, X. Chen and Z. Yang, Colloids Surf., B 2013, 108, 352-357; b) W. Lee, C. Y. Bae, S. Kwon, J. Son, J. Kim, Y. Jeong, S. S. Yoo and J. K. Park, Adv. Healthcare Mater. 2012, 1, 635-639.

[5] J. Sievers, S. Zschoche, R. Dockhorn, J. Friedrichs, C. Werner and U. Freudenberg, ACS Appl. Mater. Interfaces 2019, 11, 4186241874.

[6] Y. Li, L. Yang, Y. Zeng, Y. Wu, Y. Wei and L. Tao, Chem. Mater. 2019, 31, 5576-5583.

[7] P. K. Sharma, S. Taneja and Y. Singh, ACS Appl. Mater. Interfaces 2018, 10, 30936-30945.

[8] a) R. Guo, Q. Su, J. Zhang, A. Dong, C. Lin and J. Zhang, Biomacromolecules 2017, 18, 1356-1364; b) M. E. Smithmyer, C. C. 
Deng, S. E. Cassel, P. J. LeValley, B. S. Sumerlin and A. M. Kloxin, ACS Macro Lett. 2018, 7, 1105-1110.

[9] T. N. Gevrek, M. Cosar, D. Aydin, E. Kaga, M. Arslan, R. Sanyal and A. Sanyal, ACS Appl. Mater. Interfaces 2018, 10, 14399-14409. [10] F. Yu, X. Cao, J. Du, G. Wang and X. Chen, ACS Appl. Mater. Interfaces 2015, 7, 24023-24031.

[11] a) Y. Zhang and M. Barboiu, Chem. Rev. 2016, 116, 809-834; b) R. Deng, M. J. Derry, C. J. Mable, Y. Ning and S. P. Armes, J. Am. Chem. Soc. 2017, 139, 7616-7623; c) Y. Li, X. Wang, Y.-n. Fu, Y. Wei, L. Zhao and L. Tao, ACS Appl. Mater. Interfaces 2018, 10, 26046 26055; d) Y. Zhang, Y. Qi, S. Ulrich, M. Barboiu and O. Ramström, Mater. Chem. Front. 2020, 4, 489-506.

[12] a) Z. Wei, J. H. Yang, J. Zhou, F. Xu, M. Zrinyi, P. H. Dussault, Y. Osada and Y. M. Chen, Chem. Soc. Rev. 2014, 43, 8114-8131; b) J. Lei, X. Li, S. Wang, L. Yuan, L. Ge, D. Li and C. Mu, ACS Appl. Polym. Mater. 2019, 1, 1350-1358; c) N. Roy, B. Bruchmann and J.-M. Lehn, Chem. Soc. Rev. 2015, 44, 3786-3807.

[13] K. Miyamae, M. Nakahata, Y. Takashima and P. D. A. Harada, Angew. Chem., Int. Ed. 2015, 54, 8984-8987.

[14] a) L. Wang, F. Deng, W. Wang, A. Li, C. Lu, H. Chen, G. Wu, K. Nan and L. Li, ACS Appl. Mater. Interfaces 2018, 10, 36721-36732; b) J. Lou, F. Liu, C. D. Lindsay, O. Chaudhuri, S. C. Heilshorn and Y. Xia, Adv. Mater. 2018, 30, 1705215.

[15] Y. Zhang, M. Barboiu, O. Ramstrom and J. Chen, ACS Catal. 2020, 10, 1423-1427.

[16] Z. Su, S. Huang, Y. Wang, H. Ling, X. Yang, Y. Jin, X. Wang and W. Zhang, J. Mater. Chem. A 2020, 8, 14082-14090.

[17] Y. Zhang and M. Barboiu, Chem. Commun. 2015, 51, 1592515927.

[18] a) S. Basu, S. Pacelli and A. Paul, Acta Biomater. 2020, 105, 159-169; b) Y. Zhang, C.-Y. Pham, R. Yu, E. Petit, S. Li and M. Barboiu, Front. Chem. 2020, 8, 739.

[19] Z. Li, F. Zhou, Z. Li, S. Lin, L. Chen, L. Liu and Y. Chen, ACS Appl. Mater. Interfaces 2018, 10, 25194-25202.

[20] a) C. Shao, L. Meng, M. Wang, C. Cui, B. Wang, C.-R. Han, F. Xu and J. Yang, ACS Appl. Mater. Interfaces 2019, 11, 5885-5895; b) H. W. Ooi, S. Hafeez, C. A. van Blitterswijk, L. Moroni and M. B. Baker, Mater. Horiz. 2017, 4, 1020-1040.

[21] E. Gray, B. Mulloy and T. W. Barrowcliffe, Thromb. Haemost. 2008, 99, 807-818.

[22] S.-N. Ma, Z.-X. Mao, Y. Wu, M.-X. Liang, D.-D. Wang, X. Chen, P.-a. Chang, W. Zhang and J.-H. Tang, Cell Adhes. Migr. 2020, 14, 118-128.

[23] Z. Cai, L. Teng, J. Zhou, Y. Yan, Y. Zhang, G. Lv and J. Chen, Int. J. Biol. Macromol. 2019, 126, 612-619.

[24] M. d. P. Rodriguez-Torres, L. S. Acosta-Torres and L. A. DiazTorres, J. Nanomater. 2018, 2018, 9780489.

[25] H. M. Weber, M. V. Tsurkan, V. Magno, U. Freudenberg and C. Werner, Acta Biomater. 2017, 57, 59-69.

[26] J. You, V. K. Raghunathan, K. J. Son, D. Patel, A. Haque, C. J. Murphy and A. Revzin, ACS Appl. Mater. Interfaces 2015, 7, 1229912308.

[27] a) Y. Liang and K. L. Kiick, Acta Biomater. 2014, 10, 1588-1600; b) Y. Wang, B. Li, F. Xu, Z. Han, D. Wei, D. Jia and Y. Zhou, Biomacromolecules 2018, 19, 3351-3360.

[28] Q. Wang, Y. He, Y. Zhao, H. Xie, Q. Lin, Z. He, X. Wang, J. Li, H. Zhang, C. Wang, F. Gong, X. Li, H. Xu, Q. Ye and J. Xiao, ACS Appl. Mater. Interfaces 2017, 9, 6725-6745.

[29] J. Wu, J. Zhu, C. He, Z. Xiao, J. Ye, Y. Li, A. Chen, H. Zhang, X. Li, L. Lin, Y. Zhao, J. Zheng and J. Xiao, ACS Appl. Mater. Interfaces 2016, 8, 18710-18721.

[30] a) F. Wu, G. Meng, J. He, Y. Wu, F. Wu and Z. Gu, ACS Appl. Mater. Interfaces 2014, 6, 10005-10013; b) M. Martinez-Martinez,
G. Rodriguez-Berna, I. Gonzalez-Alvarez, M. Jesus Hernandez, A. Corma, M. Bermejo, V. Merino and M. Gonzalez-Alvarez, Biomacromolecules 2018, 19, 1294-1304.

[31] a) M. Si, W. Zhu, Y. Zhang, M. Barboiu and J. Chen, Chem. Eur. J. 2020, 26, 10191-10194; b) Z. Zhang, L. Cheng, J. Zhao, L. Wang, K. Liu, W. Yu and X. Yan, Angew. Chem. Int. Ed. 2020, 59, 1213912146; c) W. Zhou, Z. Qiao, E. Nazarzadeh Zare, J. Huang, X. Zheng, X. Sun, M. Shao, H. Wang, X. Wang, D. Chen, J. Zheng, S. Fang, Y. M. Li, X. Zhang, L. Yang, P. Makvandi and A. Wu, J. Med. Chem. 2020, 63, 8003-8024.

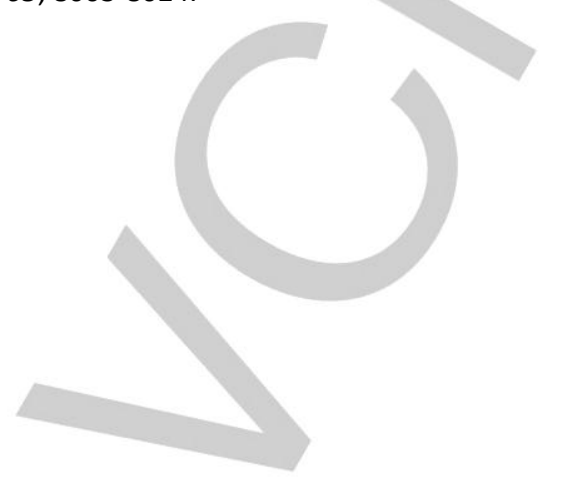


Entry for the Table of Contents

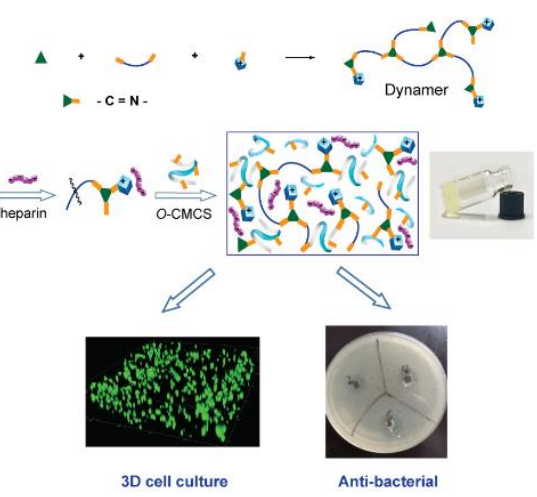

